\title{
Unpaired Drake Avoidance Behaviour and Mate Recognition by Female Mallard, Anas platyrhynchos, During the Spring Breeding Season
}

\author{
Colin M. MACKInNON ${ }^{1}$ and NAnCy M. (Lutz) MACKInNON ${ }^{2}$
}

${ }^{1}$ Environment Canada, Canadian Wildlife Service, Atlantic Region, P.O. Box 6227, Sackville, New Brunswick E4L 1G6 Canada

${ }^{2}$ Tantramar Wetlands Centre, Tantramar Regional High School, 223 Main Street, Sackville, New Brunswick E4L 3A7 Canada

MacKinnon, Colin M., and Nancy M. (Lutz) MacKinnon. 2008 Unpaired drake avoidance behaviour and mate recognition by female Mallard (Anas platyrhynchos) during the spring breeding season. Canadian Field-Naturalist 123(1): 70-71.

An observation of a female Mallard (Anas platyrhynchos) avoiding unpaired drakes, in breeding season, until reuniting with her mate after audio recognition of the rähb call. This observation supports the supposition that this vocalization by the male Mallard is a response to separation from the female and functions as a contact call in mate recognition.

Key Words: Mallard, Anas platyrhynchos, courtship, rähb call, mate recognition, Sackville Waterfowl Park, New Brunswick.

Among waterfowl, the Mallard (Anas platyrhynchos) is one of the more studied species. Drilling et al. (2002) covered in detail all aspects of Mallard life history, citing an extensive list of reference work for this species. Mallard behaviour, as it relates to mating, courtship, mate-guarding and the maintenance of the pair bond has been the focus of much research (Humburg et al. 1978; McKinney et al. 1983; Titman 1983; Goodburn 1984; Losito and Baldassarre 1996). Mallards are monogamous; however, paired males will force-mate with other females (as by pursuit flights) as well as guard their mate, especially during the period when the female is fertile. The paired female will also evade pursuit by males, other than their mate, by flying, running, hiding and/or diving (Drilling et al. 2002).

Mallards, especially the females, have a wide range of vocalizations. The less vocal male has a rähb call described as "quieter" than the female's quack (Klint 1980). Klint (1980) suggests that male Mallards respond with this rähb call when separated from their female mate; thus, this vocalization may function as a contact call. As one might expect, there is a range of male and female interactions associated with the pair bond during the breeding season as well as various responses to other influences, such as other males that might force copulation. The following observations bring together a series of behavioural responses between what were presumably a pair of Mallard ducks in avoidance of potential conflicts with other male Mallards in the near vicinity.

At 19:10 on 15 April 2008 we observed a wild female Mallard in a head-tucked, motionless resting position on a raised portion of upland adjacent to a boardwalk trail. The trail is situated within a 19 ha freshwater wetland known as the Sackville Waterfowl Park (Hanson et al. 1994). A portion of the wooden-decked trail is supported by a narrow vegetated island ( $4 \mathrm{~m}$ wide) dominated by what is believed to be a hybrid birch "Blue Birch" (Betula pendula $\times$ B. populifolia) with a diameter at breast height ( $\mathrm{dbh}$ ) ranging from 5 to $10 \mathrm{~cm}$. The understory is open with little ground cover. The female was motionless (as if sitting on a nest) and we approached, while staying on the boardwalk, to within $2 \mathrm{~m}$. While we viewed the female, two drake Mallards were seen in shallow open water, $\sim 20 \mathrm{~m}$ away through the trees, feeding and making low vocalizations (feeding chuckle call). At about 19:11 a third drake landed in the vicinity of the aforementioned two and also began to feed. Just minutes prior to the start of this observation, we noted a pursuit flight of 2 male: 1 female Mallard overhead: evidence that breeding was well underway and that females were being actively pursued.

We watched the silent motionless female for about 2 minutes when a fourth drake Mallard landed in the open water about $20 \mathrm{~m}$ behind the female and about $20 \mathrm{~m}$ away from the aforementioned feeding drakes. On landing, the drake immediately started making a low 'quacking' noise (the rähb call as described by Klint 1980); by the first or second call the female quickly raised her head and, turning $180^{\circ}$, immediately entered the water. As soon as the female began moving, the vocalizing drake proceeded to meet her and they swam parallel to each other, under cover of vegetation next to the island, away from the three drakes that were still feeding in the open water. The female and drake were still in close proximity $(<0.5 \mathrm{~m})$ when the observation ceased at 19:15. At the time of observation, wind was essentially nil, with a clear sky and mild temperatures at $14^{\circ} \mathrm{C}$.

These observations support the observation made by Klint (1980) suggesting that the rähb call is a male Mallard response to separation from its mate and thus functions as a contact call. Furthermore, these obser- 
vations place the rähb call in the context of a paired female which clearly avoided detection by other male Mallards while silently making audio mate recognition.

\section{Acknowledgments}

We thank Paul Chamberland, Peter W. Hicklin and Andrew C. Kennedy for helpful advice on the manuscript as well as review comments and suggestions by A. J. Erskine.

\section{Literature Cited}

Drilling, N., R. Titman, and F. McKinney. 2002. Mallard (Anas Platyrhynchos). In The Birds of North America, (658). Edited by A. Poole and F. Gill. The Birds of North America, Inc., Philadelphia.

Goodburn, S. F. 1984. Mate guarding in the Mallard Anas platyrhynchos. Ornis Scandinavica 15: 261-265.
Hanson A., C. Ellingwood, J. Kerekes, and A. Smith. 1994. Sackville Waterfowl Park, Sackville, New Brunswick, Canada. Baseline characterization, towards long-term monitoring. Hydrobiologica 279-280: 521-524.

Humburg, D. D., H. H. Prince, and R. A. Bishop. 1978. The social organization of a Mallard population in northern Iowa. Journal of Wildlife Management 42: 72-80.

Klint, T. 1980. On the incidence of rähb calling in male Mallard Anas platyrhynchos . Ornis Scandinavica 11: 81-84.

Losito, M. P., and G. A. Baldassarre. 1996. Pair-bond dissolution in Mallards. Auk 113: 692-695.

McKinney, F., S. R. Derrickson, and P. Mineau. 1983. Forced copulation in waterfowl. Behaviour 86: 250-294.

Titman, R. D. 1983. Spacing and three-bird flights of Mallards breeding in pothole habitat. Canadian Journal of Zoology 61: 839-847.

Received 5 December 2008 Accepted 19 June 2009 